\title{
Knowledge Transfer Activities in social sciences and humanities: Explaining the interactions of research groups with non-academic agents
}

\author{
Julia Olmos-Peñuela ${ }^{\mathrm{a}, *}$, Elena Castro-Martínez ${ }^{\mathrm{a}}$, Pablo D'Este ${ }^{\mathrm{a}}$ \\ a INGENIO (CSIC-UPV), Spanish Council for Scientific Research (CSIC) - Universitat Politècnica de \\ València (UPV), Spain \\ * Corresponding autor. Tel: +34 963877007 ext.78430. Fax: +34 963877991. \\ E-mail addresses: juolpe@ingenio.upv.es (J. Olmos-Peñuela), ecastrom@ingenio.upv.es (E. Castro- \\ Martínez), pdeste@ingenio.upv.es (P. D'Este).
}

\begin{abstract}
The aim of this research is to achieve a better understanding of the processes underlying knowledge transfer (KT) in Social Sciences and Humanities (SSH). The paper addresses: first, the extent of SSH research groups' engagement in KT and the formal KT activities used to interact with non-academic communities; and second, how the characteristics of research groups may influence engagement in various types of KT. The empirical analysis is at research group level using data derived from a questionnaire of SSH research groups conducted by the Spanish Council for Scientific Research (CSIC). We find that KT activities are based on relational rather than commercial activities. The most frequent relational activities in which SSH research groups engage are consultancy and contract research, with personnel mobility a marginal activity. We find also that the characteristics of research groups (e.g. size and multidisciplinarity) and individuals (e.g. status and research impact) are associated with involvement in KT activities and that a deliberate focus on the societal impacts and relevance of the research conducted is strongly related to active engagement of research groups in all the modes of KT considered in this study. From a managerial perspective, our findings suggest that measures promoting a focus on the societal impact of research could enhance research groups' engagement in KT activities.
\end{abstract}

Keywords: knowledge transfer activities, social sciences, humanities, research groups, science-society interactions, societal impact. 


\section{Introduction}

The relevance of knowledge for the development of modern society, and the rise of the knowledge based economy, have increased the visibility of institutions creating and disseminating knowledge (Geuna and Muscio, 2009) and put pressure on universities and public research organizations to demonstrate to funders the societal value of their research. Policy efforts focus on promoting and measuring the transfer of technology from universities and their engagement with non-academic communities. Commercial activities (i.e. licensing, spin-offs) are often used to measure knowledge transfer (KT) (see Friedman and Silberman, 2003; Link et al., 2003; Shane, 2004). Most studies and policy and academic discussion centre on transfers of science and technology knowledge (Crossick, 2009) and tend to ignore Social Sciences and the Humanities (SSH).

There are problems related to evaluating and measuring the impact of SSH research because of its less tangible and measurable results (Crossick, 2009; Molas-Gallart et al., 2000). Lack of visibility of the social value of SSH research (Olmos-Peñuela et al., 2013a) and an assumption that these disciplines have fewer links with third parties are prompting efforts to demonstrate its public value (see Bate, 2011 for case studies in the humanities). Research shows that KT in SSH involves a range of partners (firms, government agencies, non-profit organizations) and activities other than technology transfer (Hughes et al., 2011; Olmos-Peñuela et al., 2013a, 2013b). The present paper contributes to this discussion by addressing some unexplored aspects of the literature related to the heterogeneity of university-industry interactions: for instance, little is known about the university-industry interface in SSH and studies with an explicit emphasis on the group level are scarce (Gulbrandsen et al., 2011).

This paper aims to extend our understanding of KT processes in the SSH. First, we analyse the extent to which SSH research groups engage in KT to non-academic communities and identify the most frequent $\mathrm{KT}$ activities. Most empirical work on KT focuses on natural sciences and engineering disciplines (e.g. Bishop et al., 2011; D'Este and Perkmann, 2011; Haeussler and Colyvas, 2011; Landry et al., 2010, among others). This paper aims to shed light on the particularities of KT in the SSH and formal interactions that are characterized largely as relational (Perkmann and Walsh, 2007).

Second, we investigate the factors that shape the engagement of SSH research groups in different types of KT activities. We focus on the research group as the unit of analysis and on two types of factors that may drive research groups' engagement with society: factors related to the characteristics of the research group, and factors related to the characteristics of the group leader.

We focus on the research group since we contend that research is a team effort, and the group is an important organizational unit within the science system (Braam and van den Besselaar, 2010; Hernández 
et al., 2009; Rey-Rocha et al., 2008; Wuchty et al., 2007). Taking the research group as the unit of analysis contrasts with most studies of KT and science-society interactions which tend (with a few exceptions see Bercovitz and Feldman, 2011; Ramos-Vielba et al., 2010, 2012) to be at the university or researcher or university department level.

The paper is structured as follows. Section 2 discusses aspects related to the SSH research context. Section 3 reviews the main KT activities between researchers and non-academic organizations. Section 4 addresses research group determinants of KT activities. Section 5 describes the data, the methodology and the variables used in the empirical analysis presented in Section 6. Section 7 discusses the results and emerging conclusions, and their implications for managerial practice and further academic research.

\section{The context of the social sciences and the humanities}

\subsection{The policy and valorization debate}

Scientific and policy debates are usually dominated by a focus on technology transfer and commercialization activities. National research policies are aimed mostly at technology needs, and SSH research is relatively marginalized in policy formulation (Cassity and Ang, 2006). The valorization of academic results - making the results from academic research accessible to society (Bryson, 2000) - has been limited mostly to the economic contribution of universities through licensing of intellectual property rights and spin-off creation. Benneworth and Jongbloed (2010) highlight that the narrow definition of universities' societal impact is worrying since it runs the risk of overlooking the potential of the arts, humanities and social sciences.

The increasing concern about the contribution of SSH to society is reflected in a growing body of literature that provides evidence of its societal impact. In the UK context, several efforts have been made to analyse economic, cultural, policy and innovation system-level impacts of SSH research (AHRC, 2009a; Bakhshi et al., 2008; British Academy, 2004, 2008). The British Academy (2010: 3) report argues that: 'Although there has been a tendency to see STEM [Science, Technology, Engineering, Mathematics] subjects ... as the key to the success of universities and to national economic recovery, the humanities and social sciences also play a crucial part'. The Danish Business Academy report When Social Sciences and Humanities research generates profit (DEA, 2007) argues that some of the main research themes relevant 
for the business sector are covered by SSH, ${ }^{1}$ and the European HERAVALUE project ${ }^{2}$ addresses the problem of identifying the societal impacts of arts and humanities research.

The policy relevance of SSH research is highlighted by the fact that both the Seventh Framework Programme and Horizon2020 (the European Commission's future framework for research and innovation) have explicitly sought to bring the debate on the SSH contribution to society to the supranational domain, within a wider discussion of the future configuration of European research. The overall message is clear: 'The complexity of the Grand Societal Challenges demand alternative solutions and new ways to exploit our academic competences in the best and broadest way possible. This is not done by losing the Social Sciences and Humanities, but by using it' (DEA, 2011: 22).

Undoubtedly, debates concerning SSH research's contributions to society highlight the extent to which it has become a 'hot topic' in academic and policy spheres. However, the problem remains that when SSH practices are analysed through lenses built for science and technology fields, the societal contribution of SSH research is not properly captured (Olmos-Peñuela et al., 2013a). This may be due to the characteristics of SSH research and how its outputs reach the public or are exploited by non-academic communities. A better understanding of these aspects would allow a better assessment of KT in the SSH.

\subsection{The characteristics of research and how it is used}

The distinctiveness of SSH research is associated with the nature of the knowledge and how it is used (see Olmos-Peñuela et al., 2013a for further details). The contribution of SSH research to society consists of the provision of contents and the promotion of self-reflection, critical and conceptual thinking (European Commission, 2007: 9), rather than the provision of technologies more typical of engineering and experimental science fields.

More specifically, SSH research can distinctively contribute to meet societal needs by facing requirements for conceptual frames and legitimization. Beyer (1997) argues that scientific research can be used directly to solve specific problems (instrumental use) and indirectly to promote thinking and general enlightenment (conceptual use) or to sustain and legitimate an idea or position (symbolic use). Drawing on this, some authors argue that the type of knowledge generated in SSH is mainly conceptual and symbolic (Amara et al., 2004). For instance, government agencies use the knowledge provided by social scientists to articulate and legitimize the programmes they want to promote. Business organizations, from knowledge intensive businesses KIBS including the creative industries, to firms in traditional sectors, buy consulting and advice services from social scientists in order to ground their business strategies and improve their

\footnotetext{
${ }^{1}$ The SSH research themes that directly contribute to enhancing firms' innovation and growth include creativity and innovation, the ageing society and Internet behaviour and communication, among others.

${ }^{2}$ http://www.utwente.nl/mb/cheps/research/current_projects/heravalue/ (accessed 3 Sept. 2012).
} 
management of innovation (DEA, 2007; Jaaniste, 2009). Of course, there are examples of instrumental uses of SSH research ranging from the provision of contents to the cultural sector (e.g. museums, theatres, music, historic heritage, etc.), to contributions to the information and communications technology industries (e.g. linguistics, improved voice recognition technologies).

Since SSH research is concerned primarily with studying the human condition, and how individuals relate and behave and how societies are organized, research in the context of application and reflexivity are inherent characteristic of these disciplines (Gibbons et al., 1994). Although there might appear to be strong links between SSH research and societal needs, this does not imply direct engagement of researchers with the potential beneficiaries of their research activities: conducting research on social phenomena and interacting with the potential users of that research are different activities. However, direct interaction with users is critical for successful two-way flows of knowledge that give researchers an accurate understanding of the context of application and provide users with valuable knowledge whether symbolic, conceptual or instrumental.

This research aims to increase our understanding of the KT processes in the field of SSH through an investigation of modes of interaction and their drivers. We argue that the nature of SSH research will affect the type of KT activity; more specifically, we propose that since SSH research outputs are rarely in the form of technology or artefacts, their uptake by potential beneficiaries is unlikely to via intellectual property or spin-off creation and requires more relational and collaborative modes such as consultancy, contract research and joint research, among others. We argue that SSH researchers' concern over the impact and societal relevance of research for potential users is likely to be a critical trigger for their direct engagement in KT activities. The following two sections address these issues in greater detail.

\section{Knowledge transfer activities in social sciences and humanities}

Several conceptual frameworks have been developed to identify and classify university-industry interactions. Bonaccorsi and Piccaluga (1994) propose a taxonomy of university-industry relationships based on the formality and length of the collaboration and the level of organizational resources provided by the university. Molas-Gallart et al. (2002) identify 12 'third stream activities' involving academic and non-academic communities which they classify into university capabilities and university activities. Abreu et al. (2009) categorize 23 types of interactions between academics and external organizations as people based, community based, problem-solving, and commercialization activities. The UK Arts and Humanities Research Council (AHRC) conducts a research project on cultural engagement and KT, and proposes eight channels of KT including performances, exhibitions, consultations, e-engagement, to measure the outcomes from KT in the sphere of cultural activities (AHRC, 2009b). A more recent UK study proposes a 
conceptual framework grouping three categories of academic entrepreneurial activities (i.e. other than teaching and research): formal commercial activities, informal commercial activities and non-commercial activities (Abreu and Grinevich, 2013). These studies provide an overview of the conceptual efforts undertaken to identify, define and classify the range of university-industry interactions.

Empirical work on relational KT provides some insights into the dominant forms of collaboration in SSH. For example, the study conducted by Schartinger et al. shows that joint research activities are 'used predominantly by natural and technical sciences (engineering, chemistry, physics) but [are] of minor relevance in economics and social sciences' (Schartinger et al., 2002: 317). This study suggests that personnel mobility and training courses are the most important KT activities in the field of economics, and that training courses for firms and lectures to firm members are important in the fields of economics and social science. Gascoigne and Metcalfe (2005) find that consultancy (39\%) and contract research (16\%) are the most common KT activities undertaken by SSH researchers, while Hughes et al. (2011), in a study of 3,500 arts and humanities scholars, report low levels of engagement in commercialization activities, but good levels of participation in networks (61\%), public lectures (56\%) and consultancy (37\%).

In the present study we focus on mechanisms involving direct personal interactions rather than indirect channels (such as books, manuals, guides, etc.) in order to examine types of engagement that foster twoway flows of knowledge between researchers and the potential beneficiaries of research. Based on our review of the literature, we characterize formal relational KT activities according to the five types in Table 1 , that is, consultancy, contract research, joint research, training and personnel mobility.

- Table 1 about here -

We argue that interactions are likely to contribute to meeting the symbolic, conceptual and instrumental needs of users, from different angles, and through different relational KT activities. According to the literature reviewed, we examine to what extent SSH groups engage in the five types of KT activities identified, and what factors shape their involvement in these activities.

\section{Determinants of research groups' knowledge transfer activities}

Scientific research tends to be conducted by groups or teams of researchers working on a common research area, within a larger institution, and recognized as an entity by colleagues and partners (Laredo and Mustar, 2000). This has increased research interest in the individual and collective determinants of scientific productivity and research practices (Carayol and Matt, 2004, 2006; Rey-Rocha et al., 2002). The KT literature includes work that uses organizational and individual characteristics to explain researchers' 
interactions with industry (Boardman and Corley, 2008; Landry et al., 2010; Ponomariov, 2008), but few that study interactions at research group level. The roles played by particular actors in an organization can exert a critical influence on the organizational behaviour of the scientific collective; for instance, Bercovitz and Feldman (2008) show the influence of the department director on the behaviour of department members. Similarly, research group leaders may play a relevant role in orienting group practices and shaping engagement with non-academic communities. Thus, we focus on the research group and the group-leader's characteristics to analyse the factors that shape the engagement of SSH research groups in different forms of KT activities.

Given the variety and characteristics of KT activities, different factors might be related to each different form of interaction. Few empirical studies of research groups investigate the determinants of KT at the group and individual levels (for an exception see Ramos-Vielba et al., 2012). Below we review the literature on university-industry interactions to identify group-level and individual-level factors that might be associated with the propensity of the research group to engage in KT activities.

\subsection{Research group characteristics}

We consider that certain research group characteristics could be closely related to how the group engages with non-academic communities. In particular, we examine three group characteristics: the focus on the societal impact of research, the educational background of group members, and team size. A review of the empirical studies that consider these characteristics is provided below.

\section{Focus on users' needs and societal impact}

The literature on knowledge utilization suggests that there is better exploitation of university research by non-academics when research projects focus on user needs and societal impact as well as scholarly advancement (Amara et al., 2004; Landry et al., 2003). Hessels and van Lente (2008: 742) note that the 'sensitivity to the impact of the research is built from the start', pointing to the importance of societal goals for the research. Putting societal - including economic, social, cultural and environmental - impacts at the core of the research (Bornmann, 2013) shows a concern for the potential non-academic uses of the research, which might be a critical driver of direct engagement in KT activities. The empirical findings suggest a positive relation between the inclusion of societal goals and increased interactions with external agents (see van der Weijden et al., 2012 for an example in the biomedical context). A study by D'Este et al. (2013) suggests that pro-social behaviour - understood as societal awareness related to identification of potential users, production of results that benefit users, and KT intermediaries - is positively related to higher involvement of researchers in diverse KT activities such as consulting, R\&D contracts and joint research. Thus, we would expect that: 
Hypothesis 1: Research groups conducting research that places a strong focus on the societal impact of research are more likely to engage in KT activities.

\section{Research group multidisciplinarity}

According to Gibbons et al. (1994), the production of knowledge in the humanities is characterized by more permeable disciplinary frontiers. Educational diversity can affect the range and depth of the group's ability to manage knowledge (Dahlin et al., 2005) and to tackle the research challenges in an increasingly complex society. This suggests that research collaborations that combine several disciplines may result in novel approaches and novel solutions to specific problems, especially in the context of 'grand challenges' and not well defined questions (Rafols and Meyer, 2010). Thus, research groups that are more heterogeneous (based on the diversity of the educational backgrounds of their members) will likely be better equipped to take a broader perspective to research problems, to have more tools and to provide interdisciplinary based solutions to socio-economic problems (Bercovitz and Feldman, 2011). This is particularly relevant in the SSH, where human and social phenomena often need to be addressed by combining a spectrum of disciplines and different theories and methodologies. In this context, we would expect multidisciplinary research groups to have a greater capacity to respond to socio-economic needs because of their more diversified and richer knowledge.

To our knowledge, the relationship between multidisciplinarity and engagement in KT activities has been rather ignored in the literature on $\mathrm{KT}$, although SSH researchers believe that multidisciplinarity promotes higher levels of KT (Castro-Martínez et al., 2008). Analysis of multidisciplinarity within research groups should provide new evidence of the effect of disciplinary diversity on involvement in KT activities. Accordingly, we would expect that:

Hypothesis 2: The more multidisciplinary the research group, the more likely it is to engage in KT activities.

\section{Research group size}

The scale of resources contributes to attract, and collaborate with, non-academic stakeholders as it increases the capacity to participate in a wider range of research-related activities, in addition to teaching and research. Some studies analyse the influence of department size (measured as number of academic staff) on academics' interactions with industry partners. Schartinger et al. (2001) find a positive relationship between department size, and the likelihood of engaging in joint research and personnel mobility. Schartinger and colleagues show that department size is significant for explaining higher levels of science-industry interactions in the form of contract research, joint research, personnel mobility and 
training activities. Landry et al. (2010) study 1,554 Canadian researchers and show that research unit size positively influences researchers' engagement in consulting activities. Thus we would expect:

Hypothesis 3: Larger research groups are more likely to engage in KT activities.

\subsection{Individual characteristics of research group leader}

Several studies analyse the influence of researchers' characteristics on their decisions to participate in different KT activities (Boardman and Ponomariov, 2009; D'Este and Perkmann, 2011; Landry et al., 2010, among others). In a collective such as a research group, certain individuals have a major influence on its practices. A focus on the group leader is relevant since this individual exerts a powerful influence on employees' work behaviour (Yukl, 2002). In the context of research groups, we contend that the leader can directly trigger the behaviour of research group members (De Jong and Den Hartog, 2007) through decisions that establish research priorities, and by steering the work of members towards the achievement of the research objectives, and mobilizing group members' commitment. Results from individual-level studies of researchers' characteristics (such as academic status and research impact) provide indirect evidence supporting the hypotheses in the sub-sections below.

\section{Academic status}

The reward system in academia traditionally is associated with scientific publication in peer-reviewed journals (Stephan, 1996). Other activities, such as commercialization and collaborative KT, are often considered not to contribute directly to the advancement of an academic career and investing time in KT activities might be perceived as costly by academics in their early academic careers (Braxton and Del Favero, 2002; Diamond, 1993). They may prefer to concentrate on activities that count in the academic reward system in order to achieve promotion. This implies that, compared with early career researchers, more established scientists in tenured positions will be more willing to participate in commercial activities since they do not face the same pressure to publish, and enjoy greater social capital (Louis et al., 1989). Empirical studies show that academic position matters. Abreu et al. (2009) find that professors engage more heavily in commercialisation activities than readers, senior lecturers or lecturers. D'Este and Perkmann (2011) provide evidence that higher academic status is positively related to the frequency of researchers' interactions with firms through consultancy, and contract and joint research activities. Thus, we would expect that:

Hypothesis 4: Research groups whose leaders have higher academic status are more likely to engage in KT activities. 
Star scientists

The researcher's scientific reputation can affect engagement in KT activities. Previous research highlights that 'star scientists' (i.e. academics who publish more and/or publish papers with greater impact) are more likely to show successful commercialization of research results (Lowe and Gonzalez-Brambila, 2007; Zucker and Darby, 1996), which indicates a positive relationship between scholarly and commercial success. Having a star scientist leading the group may attract the attention of non-academic agents more interested in collaborating with scientists with good academic reputation or high research impact. Schartinger et al. $(2001,2002)$ measure department research quality using number of publications in foreign scholarly journals per researcher; they find that international publications are positively related to higher departmental engagement in joint research activities, but not to contract research or personnel mobility. Lowe and Gonzalez-Brambila (2007) conduct an individual-level study measuring researchers' productivity as number of journal articles published per year, and conclude that entrepreneurial faculty are more productive than their peers. Finally, Landry et al. (2010) analyse possible complementarities among different activities and show that academic publication and consulting are positively related. Therefore, we would expect that:

Hypothesis 5: Research groups whose leaders are star scientists, are more likely to engage in KT activities.

\section{Data, variables and descriptive statistics}

\subsection{Study context}

The study context is CSIC - the Spanish Council for Scientific Research, which is the largest public research organization in Spain and the third largest in Europe. CSIC is part of the Ministry responsible for research, and its primary objective is to develop and promote research in the interests of scientific and technological progress. In 2007, CSIC employed 12,885 scientists, technicians and administrators: 41\% civil servants, $37 \%$ fix term contracted personnel, and 22\% doctoral and post-doctoral researchers. The tenured researchers numbered 1,830 scientists (CSIC, 2008) spread over 125 research institutes distributed throughout Spain. The research institute constitutes the administrative unit and each institute is composed of research groups. Research activities are mainly articulated around these research groups. CSIC accounts for $6 \%$ of personnel in Spain working on publicly funded R\&D, and generates 20\% of Spain's scientific publications, a significant proportion of Spanish output.

CSIC activities range from basic research to technological developments. It is organized around eight scientific and technical areas covering a range of disciplines: 1) biology and biomedicine; 2) food science 
and technology; 3) materials science and technology; 4) physical science and technology; 5) chemical science and technology; 6) agricultural sciences; 7) natural resources; and 8) SSH. In 2007, SSH accounted for some $10 \%$ of CSIC employees, including 268 tenured researchers and more than 250 doctoral and contract researchers working in 17 research institutes and 97 research groups. An institute may be comprised of one or several research groups. CSIC SSH research groups are usually quite small more than half include fewer than five researchers - and are often multidisciplinary, covering multiple fields of science (see Table 2).

- Table 2 about here -

\subsection{Sample and data collection}

The study population consists of the 97 CSIC SSH research groups. Research groups were identified through research institute web pages and consultation with research institute directors. Data were gathered in two phases. The first phase in 2007 collected data via two questionnaires. The research group respondents were answered by the contact persons in each of the research groups, who were often the research group leaders. These contact persons provided information on research group members and their characteristics. The first questionnaire was administered face-to-face and collected information on the research group, its members, their status and their disciplinary backgrounds. The results were sent to interviewees for validation. The second questionnaire was administered to the contact persons who completed and returned it by postal mail. The postal questionnaire was comprised of a checklist of items to be scored on a four point likert scale, referring mostly to the period 2005-2007. The questionnaire was constructed based on the review of the technology transfer literature in Bozeman (2000), which we adapted to research group level to organize information related to different knowledge transfer dimensions: agent, recipient, media, object and demand environment. Although Bozeman's review is not at research group level, we considered it useful to identify and synthesize the main dimensions in the knowledge transfer process in order to construct our questionnaire.

We obtained 94 valid questionnaires from the face-to-face interviews, and 86 completed postal questionnaires. The information from both sources related to 83 research groups, representing $86 \%$ of the population and covering more than $90 \%$ of SSH researchers (Table 2).

The second data collection phase was in September 2010. Information on research group leaders' academic production and impact (publications and citations) was gathered from Thomson Reuters ISI Web of Science (WoS), and the Social Science Citations Index (SSCI) and Arts \& Humanities Citation Index (A\&HCI). We used lifetime citations data (Linmans, 2010) to collect information on citations to 
published papers by research group leaders, up to 2007. The final study sample includes the 83 research groups for which we have information at both group and individual (i.e. group leader) levels.

\subsection{Main variables}

We consider five binary dependent variables, one for each type of KT activity: consultancy, contract research, joint research, training, and personnel mobility. Each dependent binary variable takes the value 1 if the research group engaged at least once in the specific KT activity with non-academic agents during the period 2005-2007, and 0 otherwise.

For factors shaping KT activities, we include two independent continuous variables (degree of multidisciplinarity and size), referring to research group characteristics. We also include three binary independent variables: one for research group characteristics (societal impact) and two for research group leader's characteristics (status and star scientist).

The degree of multidisciplinarity is measured by the discipline of the group researcher's $\mathrm{PhD}$ qualification. ${ }^{3}$ We use the Shannon diversity index computed for each research group to obtain a measure for research group multidisciplinarity. This index reflects both the variety of disciplines and their distribution within the research group.

Shannon diversity index $=-\sum_{\mathrm{i}=1}^{\mathrm{N}} \mathrm{p}_{\mathrm{i}} \log \mathrm{p}_{\mathrm{i}}$

where $i=1$ to $\mathrm{N}$ corresponding to the number of different disciplines within each research groups, and $p_{i}$ captures the proportion of researchers belonging to the $i^{\text {th }}$ discipline in the research group (according to the scientific field of the $\mathrm{PhD}$ degree). The Shannon diversity index takes a positive value ranging from 0 if the research group is monodisciplinary (i.e. all researchers have the same disciplinary background) and increases towards infinity for higher levels of variety and evenness of distribution of disciplinary backgrounds of research group members. The computed variable degree of multidisciplinarity is measured as a continuous variable; in our sample it ranges from 0 to 2.1 and follows a normal distribution.

Research group size is measured as the number of full time equivalent research personnel in the group, excluding PhD candidates, administrative and support staff. We use probability plots to determine whether the variable size distribution matches the normal distribution. We find that observations are not clustered

\footnotetext{
${ }^{3}$ Disciplines are classified according to the UNESCO nomenclature with 4 digit disaggregation. Nomenclature downloaded on 16 Feb. 2011 from http://unesdoc.unesco.org/images/0008/000829/082946eb.pdf.
} 
around the straight line corresponding to a normal distribution and thus matched the variable size with a normal distribution using logarithmic transformation.

Similar to other studies, the measure of societal impact is based on researchers' self-reports about their focus on societal impact of their research, and users' needs (D'Este et al., 2013; Landry et al., 2007; van der Weijden et al., 2012). We constructed our measure of societal impact as follows: respondents were asked to report the extent to which their research project objectives included an explicit focus on the potential social and economic impact of their findings. The responses, originally measured as a categorical variable using a four point likert scale (from 'not at all' to 'very much') were transformed into a binary variable that takes the value 1 if the research group answers 'very much' and 0 otherwise. ${ }^{4}$

The binary variable corresponding to academic status of research group leader takes the value 1 if the group leader is a professor and 0 otherwise. In CSIC there are three categories corresponding to a permanent position (tenured scientist, scientific researcher, and research professor); we operationalized the highest status as researchers holding the position of research professor. Therefore, our binary variable differentiates among the top academic position (research professor) and lower positions (tenured scientist, scientific researcher) to assess whether the academic status is related to engagement in KT activities.

The binary variable corresponding to star scientist is constructed following a two-step procedure. First, we measure the impact of the research undertaken by research group leaders by computing the average number of citations per year and publication. For each paper, the average number of citations per year is computed as the ratio between the number of citations received, divided by the number of years from year of publication to 2007. We used Thomson Reuters ISI WoS (SSCI and the A\&HCI databases) as the source of information and applied the following formula:

Research impact index $=\sum_{i=1}^{N}\left(\frac{\text { number of citations }_{\mathrm{i}}}{\left[2007-\text { publication year }_{\mathrm{i}}\right.}\right) /$ number of publications $(N)$

where $i=1$ to $\mathrm{N}$ and captures the $\mathrm{N}$ publications of each research group leader. Since the research impact index has a skewed distribution, in a second step we identified the group of researchers with the highest research impact: those in the upper quartile of our research impact index. We constructed a binary variable star scientist that takes the value 1 if the research group leader belongs to the first quartile of the research impact index, and 0 otherwise.

\footnotetext{
${ }^{4}$ Since we are measuring self-reported perceptions, we chose to compare 'very much' against the other answers to ensure we capture those groups most concerned about the societal impact of their research compared with those whose objectives were more ambiguous.
} 
Finally, we include a binary variable to control for research group’s disciplinary area, which is coded 1 if the research group belongs to the social sciences and 0 if the research group belongs to the humanities.

A correlation matrix of the independent variables included in our analysis is presented in Appendix Table A.1. Results indicate that the highest correlation is 0.478 and corresponds to the continuous variables multidisciplinarity and size. Table A.1 column 2 reports the tolerance statistic values for these variables (reciprocal of variance inflation factors, VIF) which indicate whether an independent variable has a strong linear relationship with the other independent variables. We observe that all tolerance statistic values are much higher than 0.2 , which suggests that multicollinearity is not a concern in the regression analysis (Field, 2009). Due to the moderate size of the data set used in the regression analysis, standard errors can be larger, so it may make sense to choose '0.1' for alpha (Noymer, 2008).

\section{Results}

\subsection{Degree of engagement in KT activities and descriptive statistics}

Table 3 shows that about half of the research groups reported having engaged at least once in consultancy (51\%) and contract research (46\%) in the period 2005-2007, and more than a third of the groups had been involved at least once in joint research (39\%) and training activities (36\%). Only 13\% of the sample had participated in personnel mobility activities.

The questionnaire also asked about the participation of research groups in the transfer of property rights: no research group reported participating in technology transfer in the form of transfer of intellectual property rights (e.g. patent licensing) during 2005-2007.

In relation to research group characteristics, $25 \%$ of the research groups reported a strong focus on the potential societal impact of their research when establishing their project objectives. The variety of study backgrounds among members of the research groups ranges from 1 (21.5\% of the sample are monodisciplinary groups) to 8 for the most multidisciplinary group. Results indicate that multidisciplinarity measured by the Shannon diversity index, ranges from 0 to 2.10 with an average of 0.73. The size of the group ranges from 1 to 23 full time researchers, with an average of 5.7 researchers. For characteristics of research group leaders, research professors represent 30\% of the sample. Those with the highest computed research impact index (i.e. star scientists), represent $27 \%$ of the sample. Descriptive statistics referring to the control variable for research group area indicate that $24 \%$ of the sample belongs to the social sciences and $76 \%$ to the humanities. 
- Table 3 about here -

\subsection{Factors explaining engagement in knowledge transfer activities}

The engagement of SSH research groups in different KT activities is measured using a binary variable for each activity considered. To identify the factors related to the likelihood of a research group engaging in these KT activities, we estimate five binary logistic regressions, one for each form of KT activity considered. The final number of observations in the regressions is $\mathrm{N}=70 .^{5}$

The results of the five binary logistic regressions are summarized in Table 4 (columns 2-6). With the exception of joint research, the regression models are good predictors of whether or not research groups engage in a specific KT activity. In the case of joint research, overall the model is not significant, suggesting that the variables included in the regression do not capture adequately the variations in the engagement of research groups in joint research activities. For the remaining regressions (i.e. consultancy, contract research, training activities and personnel mobility) the four models estimated by computing the value of the likelihood ratio are significant. The equations have good predictive power, with correct predictions ranging between $71.4 \%$ and $88.6 \%$. The values of the Nagelkerke $\mathrm{R}^{2}$ (Pseudo $\mathrm{R}^{2}$ ) range between 0.245 and 0.408 , which are acceptable for qualitative dependent variable models (Landry et al., 2006: 1609). Analysis of the relationships between the independent variables considered in the study and the likelihood that the research group participates in the different KT activities is presented below.

\section{Research group characteristics}

Societal impact is a significant variable in all the regressions. More specifically, the likelihood to engage in consultancy activities, contract research, training and personnel mobility increases for research groups that have a strong focus on the societal relevance and impact of their research. For degree of multidisciplinarity, results indicate that higher diversity in the range of disciplines of research group members is significantly and positively related to higher levels of participation in contract research. However, degree of multidisciplinarity does not have a significant impact on engagement in other KT activities. Similarly, research group size is significantly associated with engagement in consultancy and contract research. The likelihood of research groups participating in these two activities increases with the number of full time research personnel in the group. Finally, when we control for the area to which the research group belongs, we find differences for two out of the five regressions. The likelihood of the

\footnotetext{
${ }^{5}$ Overall, 27 research groups were excluded from the regression because: a) we did not have information from both questionnaires (14 groups); b) there were missing data related to responses associated with the dependent variables (13 groups) see footnote to Table 3. However, all research institutes and scientific fields are represented in our working sample for the regression analysis.
} 
research group to engage in contract research increases for social science research groups compared to humanities groups, while likelihood of engagement in personnel mobility increases for humanities research groups compared to social science groups. For the other KT activities, there are no differences between scientific areas.

\section{Individual characteristics of the research group leaders}

The academic status of the research group leader is significant in three out of five regressions. The likelihood of a research group engaging in consultancy, training and personnel mobility is positively associated with high academic status research group leaders (i.e. research professors). The research impact of the research group leader is significant in two out of five regressions. More specifically, the probability that the research group engage in consultancy and contract research is positively related to research group leaders that are star scientists.

- Table 4 about here -

\section{Discussion and conclusions}

This paper explored the extent to which CSIC SSH research groups engage in different types of KT activities with non-academic communities and the factors associated with these interactions in the Spanish context. Our empirical analysis indicates that CSIC SSH research groups collaborate with external agents through a variety of KT activities, but that this involvement is related to different factors.

We found that none of the research groups reported interacting through commercial activities, that is, through patent licensing, during the period studied (2005-2007). While studies of other areas show that researchers are involved in commercial activities (such as intellectual property rights licensing and spin off creation), this does not apply to the SSH, reflecting the scarcity of patenting activity in this field. Our results suggest that KT practices within the SSH should be studied using a wider set of activities than the types of commercialization included in the technology transfer models used in technology and engineering fields.

The percentage of groups engaging in relational KT activities is similar to the levels obtained for engineering, and the natural and physical sciences. The most frequent KT activities in the SSH are consultancy and contract research, which are used to establish interactions with non-academic communities to help solve socio-economic problems, and to meet symbolic, conceptual and instrumental societal needs. These results show that the characteristics of the SSH demand an approach that prioritizes relational and collaborative activities over commercial ways of engagement. 
Research groups' engagement in personnel mobility is marginal for the groups in our sample. In the Spanish context, personnel mobility to non-academic environments is associated with leaving academia, loss of autonomy and regulatory restrictions that make it difficult for the researcher to return to a position in academia. These conditions may discourage personnel mobility to the private or public sectors, except in the case of a political appointment, in which case return to academia is assured. Overall, this might promote a preference for engagement in alternative forms of collaboration, such as provision of technical and advisory services (e.g. consultancy), which are more easily combined with a job in academia.

Our study also explored factors associated with higher engagement of SSH research groups in specific KT activities. Our results suggest that a research focus on the potential application of research findings (i.e. consideration of societal impact when setting research group strategy) is positively related to all the types of KT analysed. Research groups more concerned with societal impact of their research, exhibit higher involvement in direct interactions with the beneficiaries of their research. This implies that providing valuable knowledge to social agents is not an automatic process and requires a purposive focus on the potential applicability of research in SSH fields.

Our results indicate that more multidisciplinary groups show higher engagement in contract research activities. Since contract research often involves balancing potentially conflicting demands (i.e. scientists' motivations for scientific knowledge generation and specific problem-solving demands from clients), a diversity of skills (e.g. basic and applied) is necessary within the collective conducting this activity. The participation of research groups in contract research activity is higher for groups with a wide diversity of disciplinary backgrounds among its membership.

We find that research impact (or scientific excellence) is important for promoting research group engagement in KT activities - especially consultancy and contract research (the most frequent KT activities in the SSH). This points to the relevance of group leaders' visibility: societal agents might be more willing to collaborate with well-established and recognized researchers, particularly for advice and commissioning of original research.

Our study has some managerial implications. First, CSIC SSH research groups are involved in KT activities with non-academic communities. CSIC is a public research organization orientated to knowledge advancement, which affords tenured researchers a high level of stability. Incentives to engage in transfer activities are relatively low compared to the incentives to conduct high scientific impact research, which is the main criterion for career progress in this setting. Indicators to measure KT activity in the Spanish research system refer mainly to intellectual property/licensing, spin off creation and R\&D contracts, which is not fully representative of SSH practices. Within this institutional context, SSH researchers feel there are few incentives provided by CSIC to engage with non-academic communities (Castro-Martínez et al., 
2008). Nevertheless, we find that Spanish researchers in SSH show substantial levels of engagement in KT, confirming findings for other fields and contexts.

Second, the way that research groups conduct their research (i.e. including users' needs in their research objectives) is an important aspect influencing interactions between researchers and non-academic communities. This result points out the existence of a strong link between an explicit focus on the societal impact of research and the higher engagement in KT activities. In this sense, promoting researchers' favourable attitudes towards, and awareness of, the societal impact of their research, could be an effective initiative to enhance engagement with society.

Third, in relation to research group leaders, we found they play a crucial role in the research group's engagement in KT activities (see also Ramos-Vielba et al., 2012). The academic status of leaders and the scientific impact of their research are associated significantly with involvement of the research groups with non-academic communities. Therefore, institutional policies should be aimed at research group leaders as potential drivers of KT practices and there should be more consideration of KT activities in promotion and tenure decisions.

There are some limitations associated with measuring the impact of research in SSH based on the ISI WoS database. Standard citation indicators have been developed mainly for non-SSH disciplines and their use for humanities publications has been questioned (Amara and Landry, 2012; Linmans, 2010; Nederhof, 2006) for the following reasons: a) ISI WoS does not include the majority of SSH publications; b) many are written in languages other than English; c) most are usually published as books. Therefore, the construction of bibliometric indicators for the humanities is a debated issue and further research should consider alternative indicators to capture research impact.

In contrast to empirical work in the KT literature, this paper focuses on the research group rather than the researcher, as the unit of analysis. We are aware that this decision in the context of our study implies working with small samples which might raise questions about the robustness of the results from a multivariate analysis. However, although in absolute terms the number of observations is small, our sample accounts for about $86 \%$ of the population. Therefore, it is highly representative of the total population of CSIC SSH research groups. Nevertheless, these results should be considered preliminary and should be compared with similar research in different institutional settings.

Based on the literature on KT in non-SSH fields, future work on SSH KT should investigate several variables not considered explicitly in this study, for example, research funding sources (Gulbrandsen and Smeby, 2005; Landry et al., 2007, 2010), motivations for collaboration (D'Este and Perkmann, 2011; Lam, 2011) and the perceived barriers to academic collaboration with socio-economic agents (Tartari et al., 2012). 


\section{Acknowledgements}

The authors acknowledge the collaboration of Spanish Council for Scientific Research researchers working in social sciences and humanities institutes and the help provided by Marián Pérez-Marín in conducting the interview program. The study benefited from financial support from the Spanish National R\&D Plan (Ref.: SEJ2005-24033-E) and the Valencian Regional Government (Ref.: GV06/225). This research is framed within a broader investigation conducted by Julia Olmos Peñuela within her PhD, and supported by a fellowship funded by the Ministry of Education through the F.P.U program [AP200701850]. Thank also go to Dr. Nabil Amara and Dr. Réjean Landry from the Chair on knowledge transfer and innovation (Université Laval) for their valuable comments. Thanks are also due to the editors of Research Policy and two anonymous referees for their valuable assistance in improving the manuscript. Any errors or omissions remain the responsibility of the authors. 


\section{References}

Abreu, M., Grinevich, V., Hughes, A., Kitson, M., 2009. Knowledge exchange between academics and the business, public and third sectors. UK- Innovation Research Center (downloaded on 21 November 2011 from http://www.cbr.cam.ac.uk/pdf/AcademicSurveyReport.pdf).

Abreu, M., Grinevich, V., 2013. The nature of academic entrepreneurship in the UK: Widening the focus on entrepreneurial activities. Research Policy 42, 408-422.

AHRC, 2009a. Leading the World. The economic impact of UK arts and humanities research. AHRC (downloaded on 29 November 2011 from http://www.ahrc.ac.uk/News-andEvents/Publications/Documents/Leading-the-World.pdf).

AHRC, 2009b. Shaping metrics for HEI Cultural Engagement - Knowledge Transfer. AHRC project report.

Amara, N., Landry, R., 2012. Counting citations in the field of business and management: why use Google Scholar rather than the Web of Science. Scientometrics 93, 553-581.

Amara, N., Ouimet, M., Landry, R., 2004. New evidence on instrumental, conceptual, and symbolic utilization of university research in government agencies. Science Communication 26, 75-106.

Bakhshi, H., Schneider, P., Walker, C., 2008. Arts and humanities research and innovation. AHRC, and NESTA (downloaded on 7 November 2011 from http://www.nesta.org.uk/library/documents/artshumanities-innovation-report.pdf).

Bate, J., 2011. The public value of the humanities. Bloomsbury, London.

Benneworth, P., Jongbloed, B.W., 2010. Who matters to universities? A stakeholder perspective on humanities, arts and social sciences valorisation. Higher Education 59, 567-588.

Bercovitz, J., Feldman, M., 2008. Academic entrepreneurs: Organizational change at the individual level. Organization Science 19, 69-89.

Bercovitz, J., Feldman, M.P., 2011. The mechanisms of collaboration in inventive teams: Composition, social networks, and geography. Research Policy 40, 81-93.

Beyer, J. M., 1997. Research utilization bridging a cultural gap between communities. Journal of Management Inquiry 6, 17-22.

Bishop, K., D'Este, P., Neely, A., 2011. Gaining from interactions with universities: Multiple methods for nurturing absorptive capacity. Research Policy 40, 30-40.

Boardman, P.C., Corley, E.A., 2008. University research centers and the composition of research collaborations. Research Policy 37, 900-913.

Boardman, P.C., Ponomariov, B.L., 2009. University researchers working with private companies. Technovation 29, 142-153. 
Bonaccorsi, A., Piccaluga, A., 1994. A theoretical framework for the evaluation of university-industry relationships. R \& D Management 24, 229-247.

Bornmann, L., 2013. What is societal impact of research and how can it be assessed? a literature survey. Journal of the American Society for Information Science and Technology 64, 217-233.

Bozeman, B., 2000. Technology transfer and public policy: a review of research and theory. Research Policy 29, 627-655.

Braam, R., van den Besselaar, P., 2010. Life cycles of research groups: the case of CWTS. Research Evaluation 19, 173-184.

Braxton, J.M., Del Favero, M., 2002. Evaluating scholarship performance: Traditional and emergent assessment templates. New Directions for Institutional Research 2002 (114), 19-32.

British Academy, 2004. That Full Complement of Riches': The Contributions of the Arts, Humanities and Social Sciences to the Nation's Wealth. The British Academy (downloaded on 15 November 2011 from http://www.britac.ac.uk/templates/asset-relay.cfm?frmAssetFileID=6386).

British Academy, 2008. Punching our weight: the humanities and social sciences in public policy making. A British Academy Report (downloaded on 15 November 2011 from http://www.allea.org/Content/ALLEA/WG\%20Evaluating/Punching_our_weight.pdf).

British Academy, 2010. Past Present and Future. The public Value of the Humanities \& Social Sciences. The British Academy. (downloaded on 11 September 2013 from http://www.britac.ac.uk/news/bulletin/BAPPF.pdf).

Bryson, J.R., 2000. Spreading the message: Management consultants and the shaping of economic geographies in time and space, in: Bryson, J. R., Daniels, P.W., Henry, N., Pollard, J. (Eds), Knowledge, space, economy. Routledge, London, pp. 157-175.

Carayol, N., Matt, M., 2004. Does research organization influence academic production? Laboratory level evidence from a large European university. Research Policy 33, 1081-1102.

Carayol, N., Matt, M., 2006. Individual and collective determinants of academic scientists' productivity. Information Economics and Policy 18, 55-72.

Cassity, E., Ang, I., 2006. Humanities-industry partnerships and the 'knowledge society': The Australian experience. Minerva 44 (1), 47-63.

Castro-Martínez, E., Fernández-de-Lucio, I., Pérez-Marín, M., Criado-Boado, F., 2008. The knowledge transfer from the humanities: possibilities and characteristics. ARBOR - Ciencia Pensamiento y Cultura 184, 619-636.

Crossick, G., 2009. So who now believes in the transfer of widgets? Talk given at the Knowledge Future Conference, Warden of Goldsmiths, University of London, 16-17 October (downloaded on 15 November 2011 from 
http://www.london.ac.uk/fileadmin/documents/about/vicechancellor/So_who_now_believes_in_th e_transfer_of_widgets.pdf).

CSIC, 2008. Annual report 2007. CSIC, Madrid.

D'Este, P., Patel, P., 2007. University-industry linkages in the UK: what are the factors underlying the variety of interactions with industry? Research Policy 36, 1295-1313.

D'Este, P., Perkmann, M., 2011. Why do academics engage with industry? The entrepreneurial university and individual motivations. Journal of Technology Transfer 36, 316-339.

D'Este, P., Llopis, O., Yegros, A. 2013. Conducting prosocial research: cognitive diversity, research excellence and awareness of the social impact of research. 35th DRUID Celebration Conference 2013, Barcelona, Spain, 17-19 June (downloaded on 30 July 2013 from http://druid8.sit.aau.dk/acc_papers/786yv644gr4cpk1ttnosvr3co6el.pdf)

Dahlin, K.B., Weingart, L.R., Hinds, P.J., 2005. Team diversity and information use. Academy of Management Journal 48, 1107-1123.

De Jong, J.P.J., Den Hartog, D.N., 2007. How leaders influence employees' innovative behaviour. European Journal of Innovation Management 10, 41-64.

DEA, 2007. When Social Sciences and Humanities research generates profit (downloaded on 12 September 2012 from http://fuhu.dk/filer/DEA/Publikationer/2007/When\%20SSH\%20research\%20generates\%20profit. pdf).

DEA, 2011. The Social Sciences and the Humanities - use it don't lose it. Position paper from DEA (downloaded on 15 October 2012 from http://dea.nu/sites/default/files/DEA.euvisionspapir.enkelt.pdf).

Diamond, R.M., 1993. Instituting change in the faculty reward system. New Directions for Higher Education 81, 13-22.

European Commission, 2007. Report of the Expert Group on Humanities. Positioning Humanities Research in the 7th Framework Programme. Directorate-General for Research (downloaded on 15 October 2012 from http://ec.europa.eu/research/social-sciences/pdf/egh-report en.pdf).

Field, A., 2009. Discovering Statistics Using SPSS ( $3^{\text {rd }}$ ed.). SAGE publications Ltd, London.

Friedman, J., Silberman, J., 2003. University technology transfer: do incentives, management, and location matter? The Journal of Technology Transfer 28, 17-30.

Gascoigne, T., Metcalfe, J., 2005. Commercialisation of research activities in the humanities, arts and social sciences in Australia. CHASS Occasional Papers $\mathrm{N}^{\circ} 1$, Council for Humanities, Arts and Social Sciences (CHASS) (downloaded on 15 November 2011 from http://www.chass.org.au/papers/pdf/PAP20050501TG.pdf). 
Geuna, A., Muscio, A., 2009. The governance of university knowledge transfer: a critical review of the literature. Minerva 47, 93-114.

Gibbons, M., Limoges, C., Nowotny, H., Schwartzman, S., Scott, P., Trow, M., 1994. The case of the Humanities, in: Gibbons, M., Limoges, C., Nowotny, H., Schwartzman, S., Scott, P., Trow, M. (Eds), The new production of knowledge: the dynamics of science and research in contemporary societies. Sage, London, pp. 90-110.

Gulbrandsen, M., Mowery, D., Feldman, M., 2011. Introduction to the special section: Heterogeneity and university-industry relations. Research Policy 40, 1-5.

Gulbrandsen, M., Smeby, J.C., 2005. Industry funding and university professors' research performance. Research Policy 34, 932-950.

Haeussler, C., Colyvas, J.A., 2011. Breaking the Ivory Tower: Academic Entrepreneurship in the Life Sciences in UK and Germany. Research Policy 40, 41-54.

Hernández, N., Fernández, M., Ramos, I. 2009. The organizational structure of research groups in a regional university system. Paper presented at 9th Conference of European Sociological Association, Lisbon, 05 September.

Hessels, L.K., van Lente, H., 2008. Re-thinking new knowledge production: A literature review and a research agenda. Research Policy 37, 740-760.

Hughes, A., Kitson, M., Probert, J., Bullock, A., Milner, I., 2011. Hidden Connections: Knowledge exchange between the arts and humanities and the private, public and third sectors. AHRC, and Center for Business Research, (downloaded on 15 October 2012 from http://www.ahrc.ac.uk/News-and-Events/Publications/Documents/Hidden-Connections.pdf).

Jaaniste, L., 2009. Placing the creative sector within innovation: The full gamut. Innovation-Management, Policy \& Practice 11, 215-229.

Lam, A., 2011. What motivates academic scientists to engage in research commercialization: 'Gold', 'ribbon' or 'puzzle'? Research Policy 40, 1354-1368.

Landry, R., Amara, N., Ouimet, M., 2007. Determinants of knowledge transfer: evidence from Canadian university researchers in natural sciences and engineering. Journal of Technology Transfer 32, 561-592.

Landry, R., Amara, N., Rherrad, I., 2006. Why are some university researchers more likely to create spinoffs than others? Evidence from Canadian universities. Research Policy 35, 1599-1615.

Landry, R., Lamari, M., Amara, N., 2003. The extent and determinants of the utilization of university research in government agencies. Public Administration Review 63, 192-205.

Landry, R., Saihi, M., Amara, N., Ouimet, M., 2010. Evidence on how academics manage their portfolio of knowledge transfer activities. Research Policy 39, 1387-1403. 
Laredo, P., Mustar, P., 2000. Laboratory activity profiles: an exploratory approach. Scientometrics 47, 515-539.

Link, A.N., Scott, J.T., Siegel, D.S., 2003. The economics of intellectual property at universities: an overview of the special issue. International Journal of Industrial Organization 21, 1217-1225.

Linmans, A.J.M., 2010. Why with bibliometrics the Humanities does not need to be the weakest link: indicators for research evaluation based on citations, library holdings, and productivity measures. Scientometrics 83, 337-354.

Louis, K.S., Blumenthal, D., Gluck, M.E., Stoto, M.A., 1989. Entrepreneurs in academe: an exploration of behaviors among life scientists. Administrative Science Quarterly 34, 110-131.

Lowe, R.A., Gonzalez-Brambila, C., 2007. Faculty entrepreneurs and research productivity. Journal of Technology Transfer 32, 173-194.

Molas-Gallart, J., Salter, A., Patel, P., Scott, A., Duran, X., 2002. Measuring third stream activities. Final Report to the Russell Group of Universities. SPRU, Brighton.

Molas-Gallart, J., Tang, P., Morrow, S., 2000. Assessing the non-academic impact of grant-funded socioeconomic research: results from a pilot study. Research Evaluation 9, 171-182.

Nederhof, A.J., 2006. Bibliometric monitoring of research performance in the social sciences and the humanities: a review. Scientometrics 66, 81-100.

Noymer, A., 2008. Alpha, significance level of test, in: Lavrakas, P.J. (Ed.), Encyclopedia of Survey Research Methods. SAGE Publications Inc. DOI: http://dx.doi.org/10.4135/9781412963947.

Olmos-Peñuela, J., Benneworth, P., Castro-Martínez, E., 2013a. Are 'STEM from Mars and SSH from Venus'?: Challenging disciplinary stereotypes of researchâ's social value. Science and Public Policy, doi:10.1093/scipol/sct1071.

Olmos-Peñuela, J., Molas-Gallart, J., Castro-Martínez, E., 2013b. Informal collaborations between social sciences and humanities researchers and non-academic partners. Science and Public Policy, doi:10.1093/scipol/sct1075.

Perkmann, M., Walsh, K., 2007. University-industry relationships and open innovation: Towards a research agenda. International Journal of Management Reviews 9, 259-280.

Ponomariov, B.L., 2008. Effects of university characteristics on scientists' interactions with the private sector: an exploratory assessment. Journal of Technology Transfer 33, 485-503.

Ramos-Vielba, I., Fernandez-Esquinas, M., Espinosa-de-los-Monteros, E., 2010. Measuring universityindustry collaboration in a regional innovation system. Scientometrics 84, 649-667.

Ramos-Vielba, I., Díaz, C.; Calero, J., 2012. Researchers motivations to collaborate with industry and knowledge transfer channels. Insights from a case study. Paper presented at the Annual Meeting of the Society for Social Studies of Science (4S), Copenhagen , 17-20 October. 
Rafols, I., Meyer, M., 2010. Diversity and network coherence as indicators of interdisciplinarity: Case studies in bionanoscience. Scientometrics 82, 263-287.

Rey-Rocha, J., Martin-Sempere, M.J., Garzon, B., 2002. Research productivity of scientists in consolidated vs. non-consolidated teams: the case of Spanish university geologists. Scientometrics 55, 137-156.

Rey-Rocha, J., Martin-Sempere, M.J., Sebastian, J., 2008. Structure and dynamics of research groups. ARBOR - Ciencia Pensamiento y Cultura 184, 743-757.

Schartinger, D., Rammer, C., Fischer, M.M., Frohlich, J., 2002. Knowledge interactions between universities and industry in Austria: sectoral patterns and determinants. Research Policy 31, 303328.

Schartinger, D., Schibany, A., Gassler, H., 2001. Interactive relations between universities and firms: empirical evidence for Austria. The Journal of Technology Transfer 26, 255-268.

Shane, S.A., 2004. Academic entrepreneurship. University spinoffs and wealth creation. Edward Elgar Cheltenham, UK.

Stephan, P.E., 1996. The economics of science. Journal of Economic literature 34, 1199-1235.

Tartari, V., Salter, A., D'Este, P., 2012. Crossing the Rubicon: exploring the factors that shape academics' perceptions of the barriers to working with industry. Cambridge Journal of Economics 36, 655677.

van der Weijden, I., Verbree, M., van den Besselaar, P., 2012. From bench to bedside: The societal orientation of research leaders: The case of biomedical and health research in the Netherlands. Science and Public Policy 39, 285-303.

Wuchty, S., Jones, B.F., Uzzi, B., 2007. The increasing dominance of teams in production of knowledge. Science 316, 1036.

Yukl, G., 2002. Leadership in Organisations (5th ed). Prentice-Hall, Englewood Cliffs, NJ.

Zucker, L.G., Darby, M.R., 1996. Star scientists and institutional transformation: patterns of invention and innovation in the formation of the biotechnology industry. Proceedings of the National Academy of Sciences 93 (23), 12709-12716. 
Tables

Table 1

Definitions of KT activities.

KT activities $\quad$ Definitions

Consultancy

Technical advice services work commissioned by non-academic agents that do not necessary involve original academic research.

Contract research Original research activities carried out by academics and commissioned by non-academic organizations

Joint research

Original research activities involving formal collaborative arrangements to conduct research undertaken by academic and non-academic organizations.

Training

Learning activities, such as courses, offered by the academic community (or demanded by nonacademics) which are tailored to socio-economic agents' needs (business, government and professional groups). They are usually short term and targeted to deal with a limited range of issues. This activity is different from traditional and formalized courses such as degree or masters courses.

Personnel mobility

Flow of academics to other social environment (e.g. secondments to firms or to public agencies), as a way to further develop the expertise generated in the academic sphere to solve societal or economic problems as well as to learn from the context of application.

Source: based on Abreu and Grinevich (2013); D'Este and Patel (2007); Molas-Gallart et al. (2002). 
Table 2

Population and sample distribution by institutes and fields.

\begin{tabular}{|c|c|c|c|c|c|c|c|}
\hline \multirow[b]{2}{*}{ Area } & \multirow[b]{2}{*}{ Acronym } & \multirow[b]{2}{*}{ Institutes } & \multirow[b]{2}{*}{ Main fields covered } & \multicolumn{2}{|c|}{ Population } & \multicolumn{2}{|c|}{ Sample } \\
\hline & & & & $\begin{array}{c}\text { Research } \\
\text { Groups } \\
(\mathrm{N})\end{array}$ & $\begin{array}{l}\text { Researchers } \\
\quad *(\mathrm{~N})\end{array}$ & $\begin{array}{l}\text { Research } \\
\text { Groups } \\
(\mathrm{N})\end{array}$ & $\begin{array}{l}\text { Researchers } \\
\quad *(\mathrm{~N})\end{array}$ \\
\hline $\mathrm{H}$ & $\mathrm{IH}$ & Institute of History & $\begin{array}{l}\text { Prehistory, ancient history, medieval history modern } \\
\text { history, comparative history, history of art, Greco-Latin } \\
\text { and biblical heritage studies, historiography. }\end{array}$ & 22 & 125 & 17 & 102 \\
\hline $\mathrm{H}$ & IMF & Milá and Fontanals Institution & $\begin{array}{l}\text { Archaeology, anthropology, ethnography, medieval } \\
\text { studies, history of science, musicology }\end{array}$ & 10 & 56 & 10 & 56 \\
\hline $\mathrm{H}$ & ILLA & $\begin{array}{l}\text { Institute of Language, Literature, and } \\
\text { Anthropology }\end{array}$ & Language, literature, anthropology & 10 & 42 & 9 & 37 \\
\hline $\mathrm{H}$ & ILC & $\begin{array}{l}\text { Institute of Languages and Cultures of the } \\
\text { Mediterranean and the Near East }\end{array}$ & $\begin{array}{l}\text { Philology, lexicography, lexicology, palaeography, } \\
\text { historical studies }\end{array}$ & 9 & 48 & 9 & 48 \\
\hline $\mathrm{H}$ & IFS & Institute of Philosophy & Philosophy, ethics, history of science & 4 & 27 & 3 & 24 \\
\hline $\mathrm{H}$ & IEIOP & $\begin{array}{l}\text { Institute of Islamic and Near Eastern } \\
\text { Studies }\end{array}$ & $\begin{array}{l}\text { Ancient history, medieval history, epigraphy, philology, } \\
\text { historiography }\end{array}$ & 4 & 20 & 3 & 18 \\
\hline $\mathrm{H}$ & IHCD & $\begin{array}{l}\text { López Piñero Institute for the History of } \\
\text { Medicine and Science }\end{array}$ & $\begin{array}{l}\text { Historical studies on science, technology and society, } \\
\text { contemporary medicine studies, sociology of science }\end{array}$ & 4 & 19 & 3 & 16 \\
\hline $\mathrm{H}$ & EEHA & School of Hispano-American Studies & $\begin{array}{l}\text { Modern history , contemporary history, historical } \\
\text { geography, cultural anthropology }\end{array}$ & 3 & 20 & 3 & 20 \\
\hline $\mathrm{H}$ & EEA & School of Arabic Studies & $\begin{array}{l}\text { Architectural history, historiography, epigraphy, } \\
\text { philology, medieval history }\end{array}$ & 3 & 9 & 3 & 9 \\
\hline $\mathrm{H}$ & IEGPS & $\begin{array}{l}\text { Padre Sarmiento Institute for Galician } \\
\text { Studies }\end{array}$ & Archaeology, architectural history, heritage studies & 2 & 13 & 2 & 13 \\
\hline $\mathrm{H}$ & IAM & Mérida Institute of Archaeology & $\begin{array}{l}\text { Archaeology, history of art, architectural history, } \\
\text { historical geography }\end{array}$ & 1 & 7 & 1 & 7 \\
\hline SS & IEGD & $\begin{array}{l}\text { Institute of Economics, Geography and } \\
\text { Demography }\end{array}$ & Economics, geography, demography & 11 & 40 & 8 & 35 \\
\hline SS & IEDCYT & $\begin{array}{l}\text { Institute of Documentary Studies on } \\
\text { Science and Technology }\end{array}$ & Information sciences, science policy, history of science & 7 & 18 & 6 & 17 \\
\hline SS & IPP & Institute of Public Goods and Policies & Political sciences, sociology & 4 & 25 & 3 & 19 \\
\hline SS & IAE & Institute for Economic Analysis & Economics & 1 & 23 & 1 & 23 \\
\hline SS & IESA & Institute for Advanced Social Studies & Sociology & 1 & 15 & 1 & 15 \\
\hline \multirow[t]{2}{*}{ SS } & INGENIO & $\begin{array}{l}\text { Institute of Innovation and Knowledge } \\
\text { Management }\end{array}$ & Economics, political sciences, sociology & 1 & 13 & 1 & 13 \\
\hline & & TOTAL (\%) & & 97 & 520 & $\begin{array}{c}83 \\
(85.6 \%)\end{array}$ & $\begin{array}{c}472 \\
(90.6 \%)\end{array}$ \\
\hline
\end{tabular}

${ }^{*}$ Includes contracted and tenured researchers from other institutions linked to CSIC through agreements. H: Humanities; SS: Social Sciences. 
Table 3

Descriptive statistics $(\mathrm{N}=83)^{\mathrm{a}}$

\begin{tabular}{|c|c|c|c|c|}
\hline Variables & Minimum & Maximum & Mean & St. deviation \\
\hline \multicolumn{5}{|l|}{ Continuous Variables } \\
\hline - $\quad$ Size & 1 & 23 & 5.69 & 3.52 \\
\hline - $\quad$ Multidisciplinarity & 0 & 2.10 & 0.73 & 0.51 \\
\hline \multicolumn{5}{|l|}{ Binary Variables } \\
\hline - Consultancy & 0 & 1 & 0.51 & 0.50 \\
\hline - Contract research & 0 & 1 & 0.46 & 0.50 \\
\hline - Joint research & 0 & 1 & 0.39 & 0.49 \\
\hline - $\quad$ Training & 0 & 1 & 0.36 & 0.48 \\
\hline - $\quad$ Personnel mobility & 0 & 1 & 0.13 & 0.34 \\
\hline - Societal impact & 0 & 1 & 0.25 & 0.44 \\
\hline - $\quad$ Status (professor=1) & 0 & 1 & 0.30 & 0.46 \\
\hline - $\quad$ Star scientist & 0 & 1 & $0.27^{b}$ & 0.44 \\
\hline - $\quad$ Area (social sciences=1) & 0 & 1 & 0.24 & 0.44 \\
\hline
\end{tabular}

a $\mathrm{N}=70$ for the variables corresponding to the five knowledge transfer activities.

${ }^{b}$ Due to cases with the same values for research impact, star scientists represent $27 \%$ rather than the $25 \%$ corresponding to the upper quartile of the research impact index. 
Table 4

Relationship between research groups' engagement in KT activities and characteristics of research group and individual (leader): binary logistic regressions.

\begin{tabular}{|c|c|c|c|c|c|}
\hline & Consultancy & Contract research & Joint Research & Training & Personnel mobility \\
\hline Constant & - $1.927(0.787)$ & - $3.657(0.938)$ & - $1.204(0.703)$ & - $1.164(0.728)$ & - $1.867(1.136)$ \\
\hline \multicolumn{6}{|l|}{ Group variables } \\
\hline - Societal impact & $1.979^{* * *}(0.734)$ & $0.938 *(0.648)$ & $0.819 *(0.560)$ & $1.667 * * *(0.687)$ & $1.256^{* *}(0.757)$ \\
\hline - Multidisciplinarity & $-0.286(0.601)$ & $0.993 *(0.735)$ & $0.194(0.598)$ & - $0.618(0.659)$ & $1.062(0.902)$ \\
\hline - $\quad$ Size (ln) & $0.685 *(0.504)$ & $1.096 * *(0.576)$ & $0.156(0.455)$ & $0.276(0.480)$ & $-1.045(0.824)$ \\
\hline \multicolumn{6}{|l|}{ Individual variables (Leader) } \\
\hline - $\quad$ Status (professor) & $1.124 * *(0.667)$ & $0.151(0.748)$ & $-0.381(0.596)$ & $1.018 * *(0.571)$ & $1.928 * * *(0.826)$ \\
\hline - Star scientist & $1.289 * *(0.781)$ & $1.289 * *(0.795)$ & $0.589(0.662)$ & $-0.114(1.029)$ & $-0.641(1.540)$ \\
\hline \multicolumn{6}{|l|}{ Control variable } \\
\hline - $\quad$ Area (social sciences) & $-0.176(0.768)$ & $1.928 * * *(0.813)$ & $0.233(0.638)$ & $-0.966(0.811)$ & $-2.025^{* *}(1.147)$ \\
\hline Number of observations & 70 & 70 & 70 & 70 & 70 \\
\hline Chi-square (d.f.) & $14.81(6)^{* *}$ & $16.78(6)^{* *}$ & $3.93(6)$ & $10.76(6)^{*}$ & $10.55(6)^{*}$ \\
\hline Nagelkerke R² (pseudo R²) & 0.300 & 0.408 & 0.071 & 0.245 & 0.272 \\
\hline Percentage of correct predictions & 71.4 & 72.9 & 61.4 & 72.9 & 88.6 \\
\hline
\end{tabular}

Dependent variables: engagement in five KT activities.

One tailed t-test: ${ }^{*} \mathrm{p}<0.10 ;{ }^{* *} \mathrm{p}<0.05 ;{ }^{* * *} \mathrm{p}<0.01$. Robust standard errors between brackets. 


\section{Appendix A}

Table A1

Non-parametric correlations between independent variables.

\begin{tabular}{lccccc}
\hline Variables & $\begin{array}{c}\text { Tolerance } \\
\text { statistics }\end{array}$ & Multidisciplinarity & Size $(\mathrm{In})$ & Status & Star scientist \\
\hline Societal impact & 0.957 & -0.045 & -0.113 & 0.101 & -0.098 \\
Multidisciplinarity & 0.731 & 1 & 0.478 & -0.115 & 0.126 \\
Size $(\mathrm{In})$ & 0.712 & & 1 & 0.088 & 0.148 \\
Status & 0.911 & & & 1 & 0.201 \\
Star scientist & 0.913 & & & & 1 \\
\hline
\end{tabular}

Number of observations $=83$. 